\title{
Giant inguinoscrotal hernia repair
}

\author{
Prochotsky A, Dolak S, Minarovjech V, Medzo I, Hutan M, Mifkovic A \\ 2nd Department of Surgery of Commenius University Bratislava, Bratislava, Slovakia. \\ prochotsky@pe.unb.sk
}

\begin{abstract}
Giant inguinoscrotal hernia is defined as an inguinal hernia extending below the midpoint of inner thigh in standing position. The authors describe giant inguinoscrotal hernia and small umbilical hernia with 12 years history of this uncommon disease. After preoperative evaluation, US and CT examination he was operated on. It was very difficult to return the hernia sac contents back to the abdomen and additional infraumbilical incision was needed. Hernioplasty suo modo without mesh was done. Patient recovered uneventfully. In the discussion the authors present the newer classification of giant inguinal hernia, the current treatment options and known serious complications of surgery. Finally, it indicates that good treatment results can only be achieved by close cooperation of concerned professionals in the treatment and intensive intraoperative and postoperative patient monitoring (Fig. 9, Ref. 31). Text in PDF www.elis.sk.

KEY WORDS: giant inguinoscrotal hernia, newer classification and treatment, complications of surgery - intraabdominal hypertension, scrotal hematoma and redundant skin, recurrence.
\end{abstract}

\section{Introduction}

Inguinal hernia is a well known surgical disease with high incidence. History of treatment of inguinal hernia is very long and originates in ancient times (Lau, 2002). There is a lot of surgical techniques which evolved, developed and changed since. Tensionfree repair of groin hernia with different types of prosthetic mesh is currently very popular between general surgeons. A lot of them prefer laparoscopic surgery in the treatment of this entity. But this approach is not suitable for the giant inguinal or inguinoscrotal hernia repair.

Giant inguinoscrotal hernias have been defined as those that extend below the midpoint of the inner thigh when the patient is in the standing position (Hodgkinson and Mcllrath, 1980). Such giant hernias are uncommon in modern surgical practice. In high income countries inguinal hernia is usually diagnosed early, when the patient notices the development of swelling or groin pain. Given the potential hernia incarceration, surgical correction is often carried out without any delay (Tarchouli et al, 2015).

There are multiple causes of these hernias: neglecting gradually enlarging hernia, shyness of patient, lower level of medicine in the particular area and availability of qualified professionals, but also concerns of the patient and surgeon related to the result of the operation with a potential life risk.

The patients may have been previously denied surgery because of the risk of respiratory compromise with potentially fatal cardio-

2nd Department of Surgery of Commenius University Bratislava, Bratislava, Slovakia

Address for correspondence: A. Prochotsky, MD, PhD, 2nd Department of Surgery of Commenius University Bratislava, Antolska 11, SK-851 07 Bratislava, Slovakia.

Phone: +421.2.68673330 respiratory failure. Sometimes these hernias reflect the ignorance and negligence of potentially dangerous problems in developing countries, faith of people in alternative systems of medicine and to some extent, the inability of modern medical facilities to reach an ordinary human being even in heart of big cities such as New Delhi (Tahir et al, 2008). But generally, they are more common in the rural population, affecting the quality of life adversely (Karthikeyan et al, 2014).

The size of the hernia causes difficulty in walking, sitting, and lying down. Complications of giant inguinoscrotal hernia include urinary retention, leakgae, infection, skin maceration, hernia incarceration, and social isolation (Brondfield and Dhaliwal, 2016).

Finally, the number of these hernias is not confirmed by the fact that the literature references tend to be only in the form of case reports or a very small groups of patients.

There is no standard surgical procedure for the treatment of this unusual and challenging type of groin hernia. Various surgical techniques have been reported in previous publications. Precise management of surgical treatment of giant inguinoscrotal hernia is very important because there are specific problems known loss of domain, high risk for recurrence, residual scrotal skin and scrotal haematoma (Ek et al, 2006, Kyle et al, 1990, Mehendale et al, 2000, Kovachev et al, 2010, Tahir et al, 2008).

In general, close cooperation between the surgeon, the urologist, the plastic surgeon and the anaesthetist is very important resulting in good outcomes.

A 69-year-old male with giant inguinoscrotal hernia and small umbilical hernia was admitted at 2nd Department of Surgery of Commenius University and University Hospital in Bratislava. He was retired secondary school teacher. He has been affected by long-standing and gradually enlarging recurrent right inguinal hernia for the past 12 years. Patient's main complaint was 

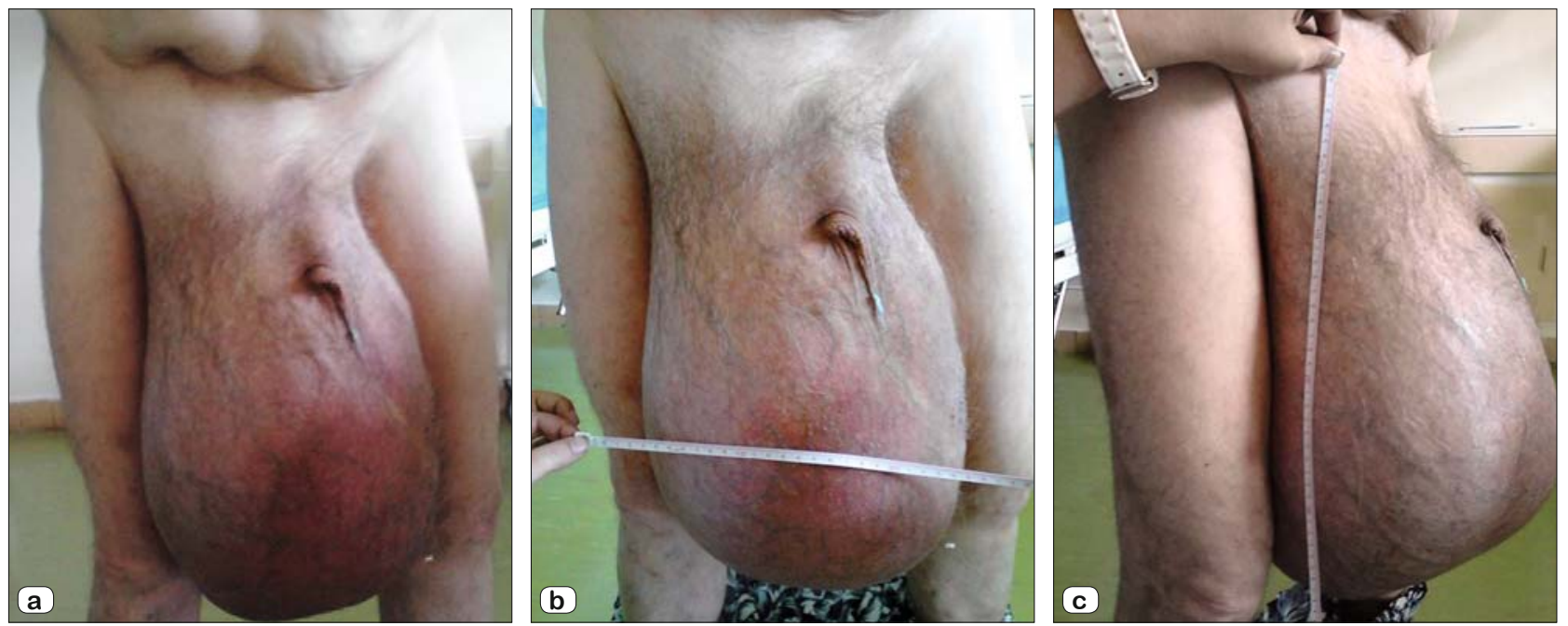

Fig. 1 a,b,c. The hernial sac in standing position extened below the superior border of patellar bone - type III of giant inguinoscrotal hernia.
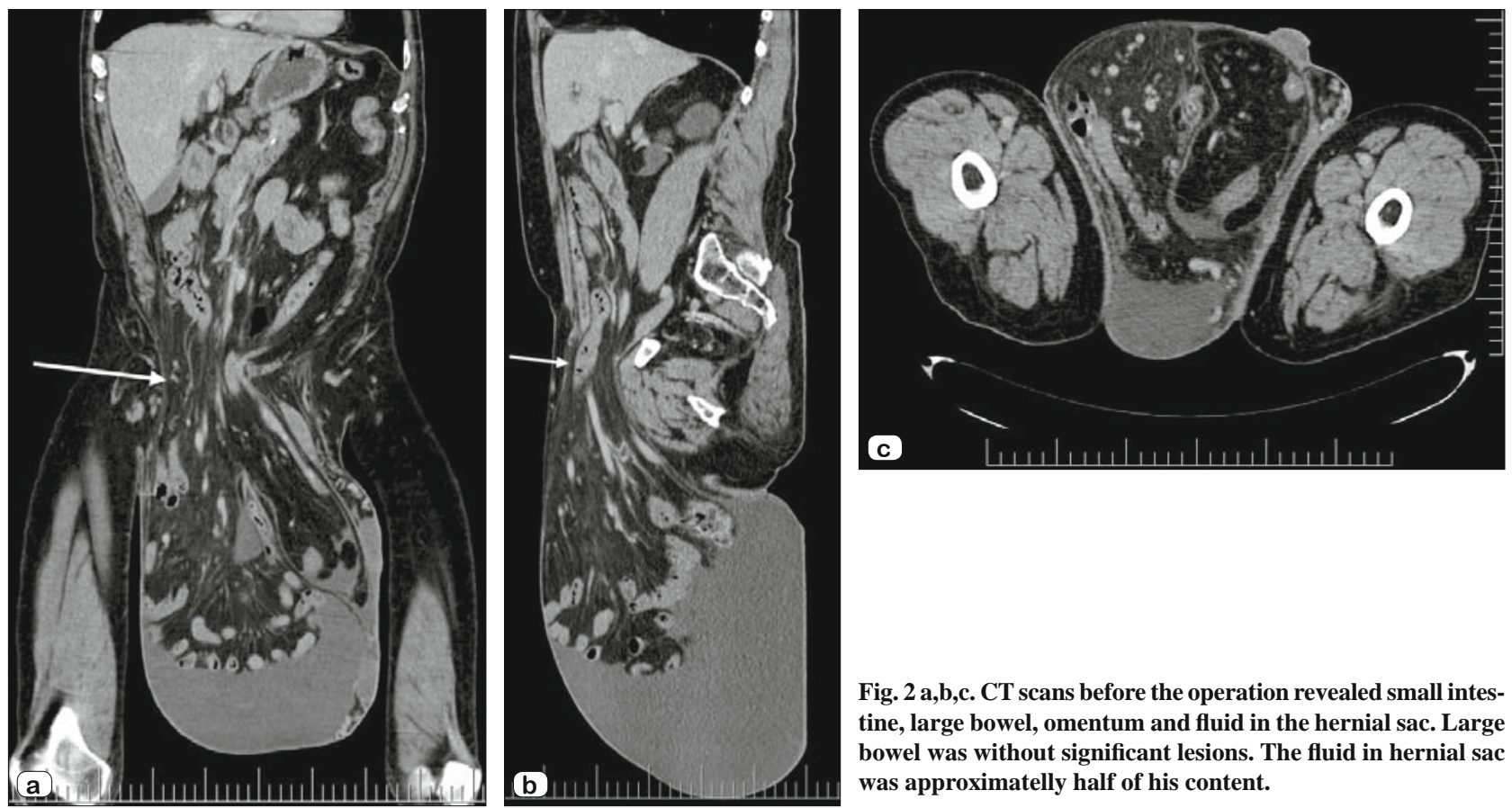

Fig. 2 a,b,c. CT scans before the operation revealed small intestine, large bowel, omentum and fluid in the hernial sac. Large bowel was without significant lesions. The fluid in hernial sac was approximatelly half of his content.

difficulty in walking. Because of the giant hernia he had to wear tailored trousers.

He had previously refused any surgical treatment and the hernia acquired enormous dimensions.

He had no abdominal or gastrointestinal complaints, but complained of occasionally difficulty in voiding. He had history of cerebral stroke years ago and arterial hypertension of grade 3 ESC/ESH.

Physical examination revealed an irreducible giant, right inguinoscrotal hernia that extended to the knee level. His penis was buried inside the scrotum, but his scrotal skin was without inflamation, ulceration or secondary infection (Figs 1 a,b,c).
As a side note, we would like to mention that when the patient later opted for surgery, he was refused to be operated on in three university hospitals.

He had had ultrasonography (US) of scrotum and then native and contrast CT examination of the scrotum and the abdomen. The content of large hernial sac ( $400 \times 235 \mathrm{~mm})$ with internal ring 80 x $45 \mathrm{~mm}$ consisted of small intestine, large bowel, omentum and fluid. The fluid in hernial sac represented approximatelly half of the content. CT scans revealed nephrolithiasis in the left kidney, small calculus in the bladder and enlarged prostate. No other serious pathology was present in the abdominal cavity and pelvis minor (Figs 2 a,b,c). 

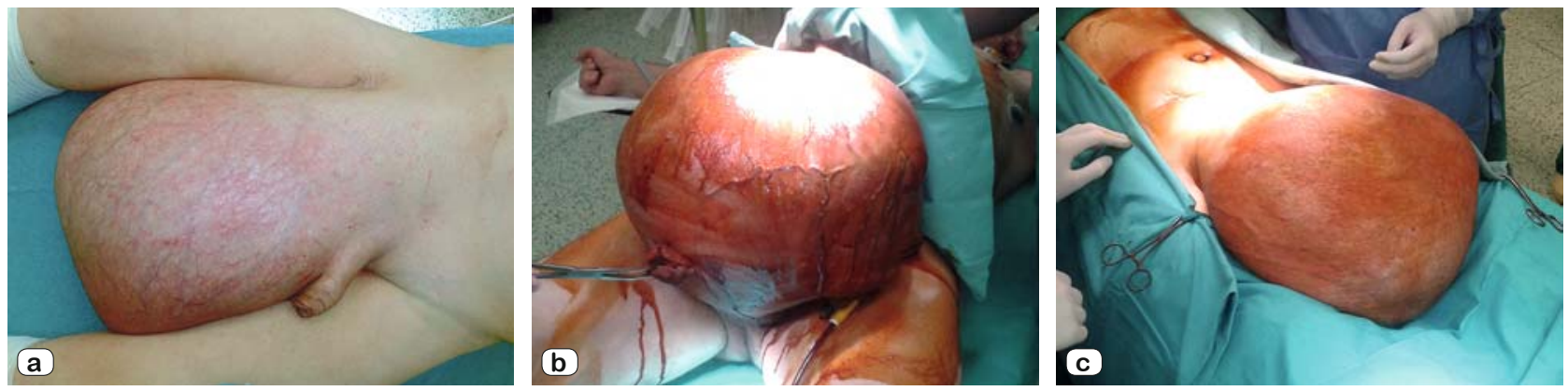

Fig. 3 a,b,c. Patient on the operating table - disinfection of the surgical field.
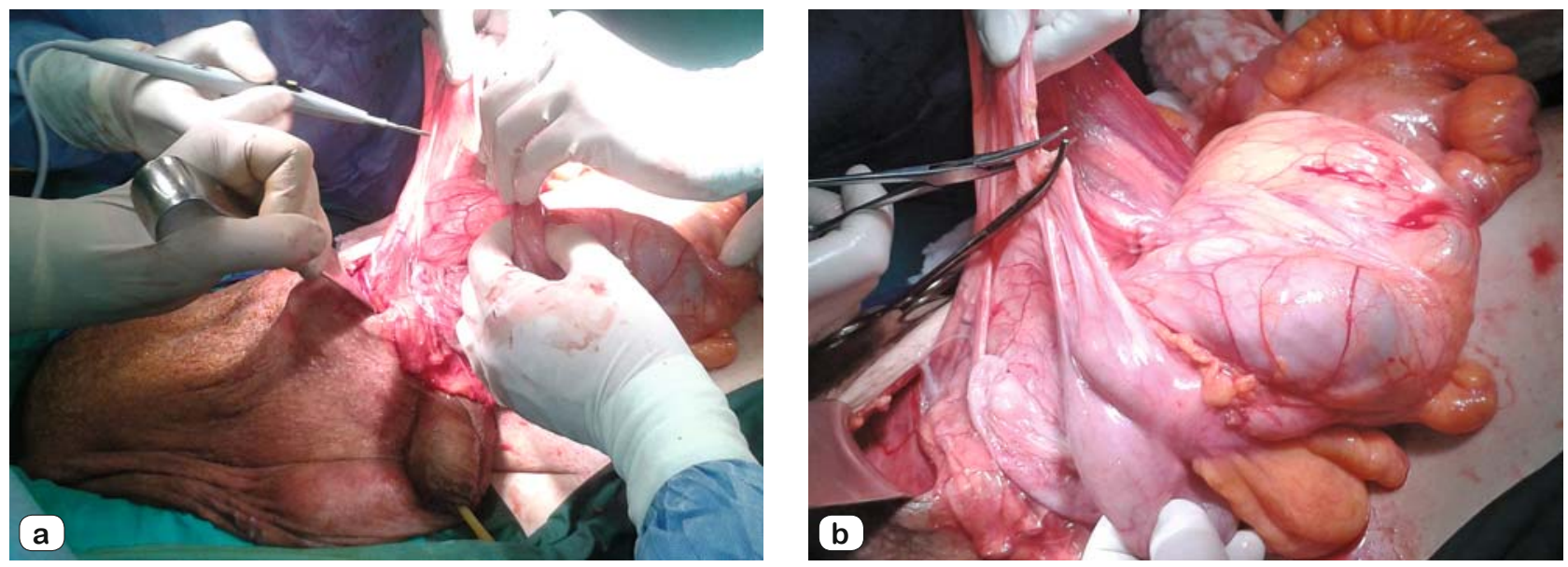

Fig. 4 a,b. Intraoperative finding: the huge hernial sac contains ileum, cecum, part of colon descendens, colon sigmoideum and part of omentum majus.
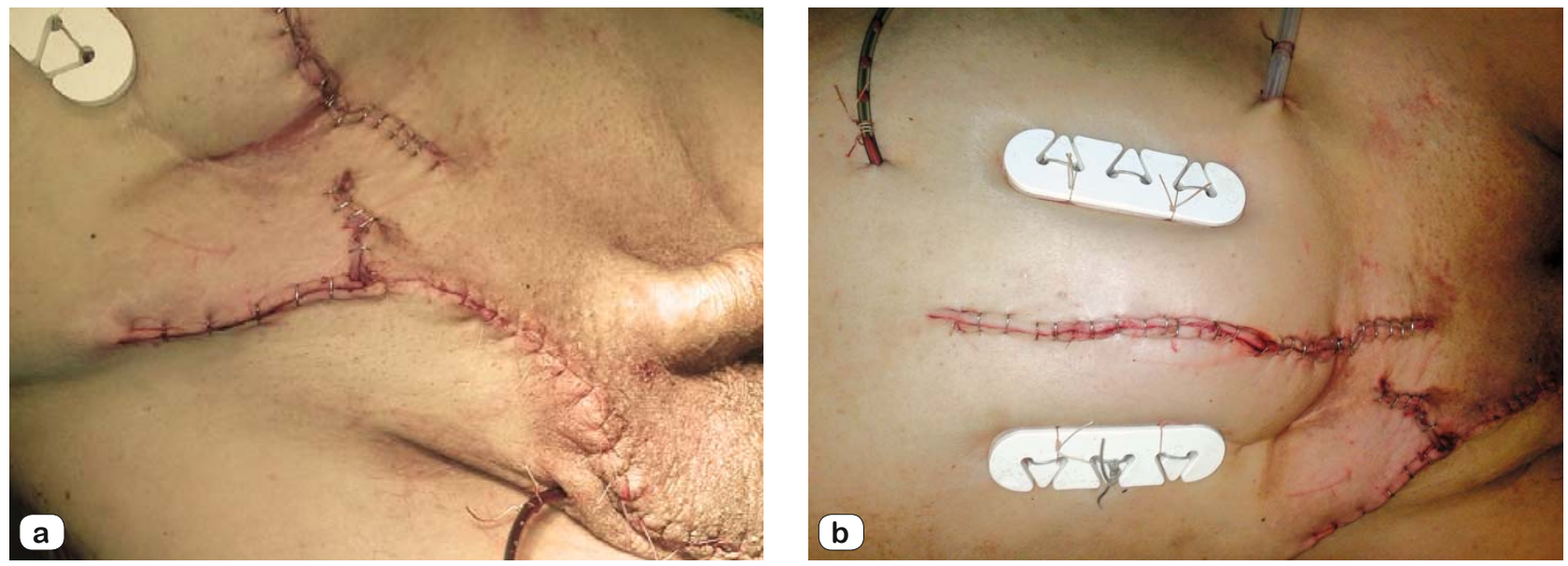

Fig. 5 a,b. Result of the operation - operating wounds and relieving the stitch of Ventrofil used to relieve suture of laparotomy and preventing its breakdown.

After receiving results of laboratory tests, ECG, X-ray of lungs and functional pulmonary tests, preoperative evaluation of actual patient's status was performed. The proceudre consisted of internal, neurologic, phtiseologic, urologic, anesthesiologic, and plastic surgery examination. In the afternoon of the day before the operation the patient underwent a bowel preparation by ortograde lavage of hollow tube of gastrointestinal tract. At midnight before the operation, the patient received a preventive dose of low molecular weight heparine (LMWH).

Surgical team consisted of general surgeon, urologist and plastic surgeon. After general ansthesia was administered, standard transverse incision at right inguina with increases to right hemiscrotum was performed. When the large hernia sac was opened under pressure, a straw-colored fluid leaked out from the sac. We 


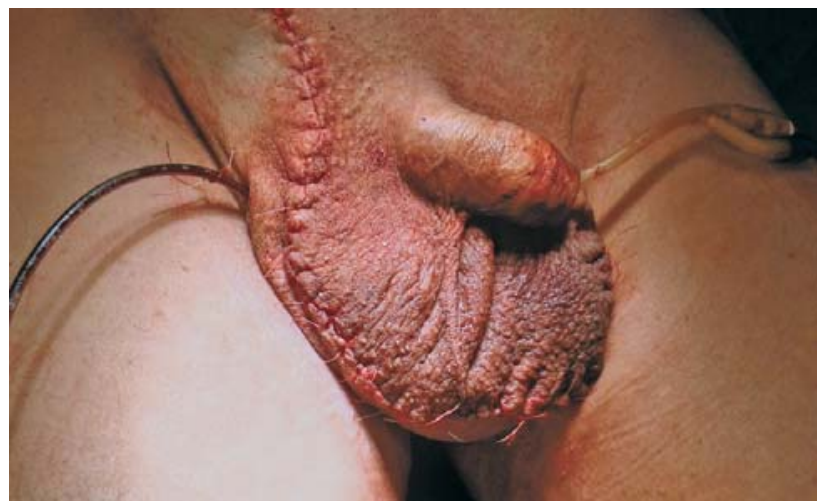

Fig. 6. Result of the operation - resected abundant scrotal skin and neoscrotum with Redon's drain inserted.
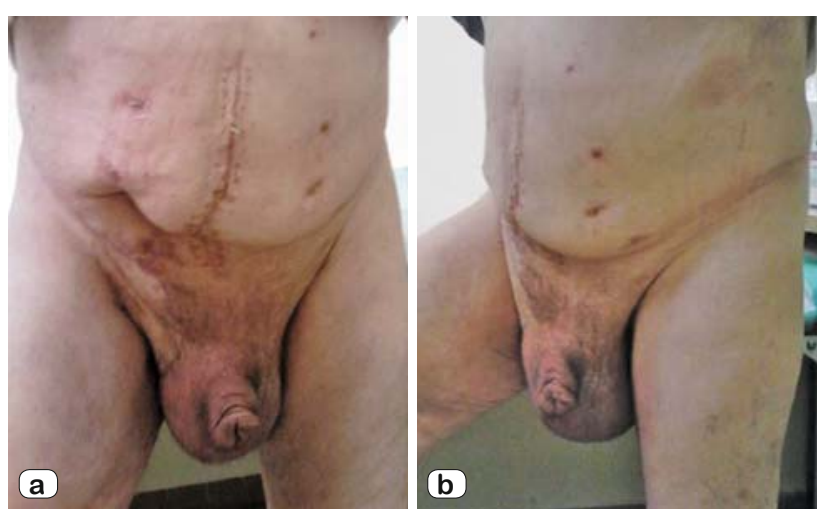

Fig. 7 a,b. State after extraction the Ventrofil stitch -3 weeks after the operation.

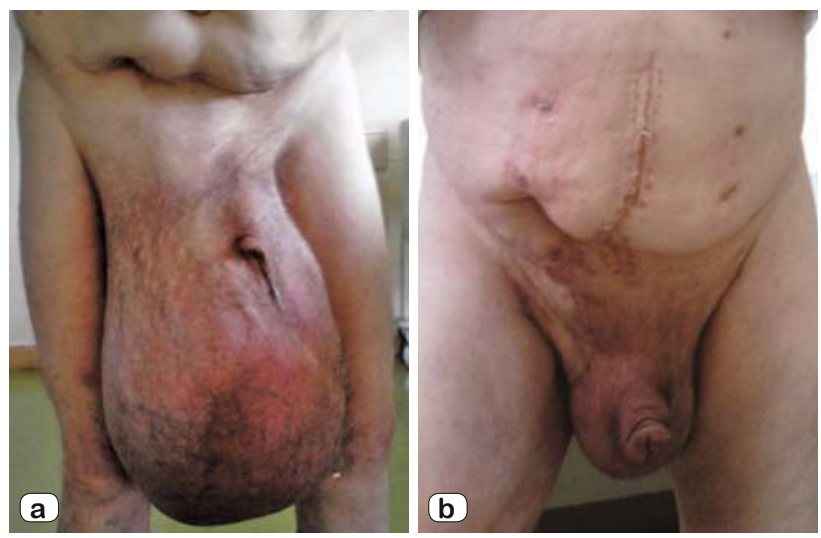

Fig. 8 a, b. For comparison: state before the surgery and 6 months after the operation.

collected atotal of $6500 \mathrm{ml}$ of this fluid. After the hernial sac was more open, terminal ileum, cecum and greatly elongated colon sigmoideum were found inside the hernial sac (Figs 3 a,b,c and 4 a,b).

Due to the dense adhesions it was very difficult to identify the right testis, which was atrophic, so the urologist made orchiectomy. Later an attempt was made at manual reduction of the hernial sac contents, but it was unsuccessful due to the massive size of that. At this stage of the operation surgeon lateral extension of internal ring was performed and manual reduction of the contents into the abdominal cavity was reattempted, but it was again unsuccessful. There was a real threat of injury to the intestine and surgeon decided to do infraumbilical midline laparotomy. Then a combination of pressure from below and pull from the abdomen through enhanced internal ring and laparotomy enabled successful repositioning of the sac content into the abdominal cavity. Internal ring was repaired with interrupted Vicryl 2-0 stitches and plastica of right inguinal hernia „suo modo“ with 2-0 Prolene interrupted stitches was done, which is different from the Lichtenstein 's tension free technique with mesh used by most authors of the recent past. After exploring the abdominal cavity, laparotomy was closed using one decompressing stitch of Ventrofil (Figs 5 a,b).

At the end of the operation plastic surgeon excided redundant scrotal skin and reconstructed neoscrotum in which vacuum Redon's drain was placed (Fig. 6). The operation lasted 6 hours from incision to the last stitch.

After the operation the intubated patient was immediately moved to the anesthesia department. On the first day after the operation the patient was on artificial lung ventilation and had his intraabdominal pressure (IAP) monitored by intravesical catheter. IAP marginally elevated for short time. On the second day the patient was extubated, he had normal oxygen saturation without a need for respiratory support. On the third day after the operation the patient was returned to the department of surgery. He had small swelling of the scrotum which gradually resorbed. Drain from right hemiscrotum - neoscrotum was extracted on the fifth postoperative day. Patient recovered uneventfully and he was discharged from the hospital on the twelfth postoperative day. The Ventrofil decompressing stitch was removed 3 weeks after the operation (Figs $7 \mathrm{a}, \mathrm{b}$ ). Currently, the patient is two and a half years after the surgery. He is fine and without evidence of recurrent inguinal hernia (Figs 8 a,b).

\section{Discussion}

Giant inguinal hernias are defined as those which extend below the midpoint of inner thigh in standing position (Lau, 2002). An older definition describes it as bigger than an average human head (Davey, 1987). New classification of giant inguinal hernias and recommended procedures were suggested by Trakarnsagna and co-authors in 2014 (Trakarnsagna et al, 2014). They categorize giant inguinal hernia into three types, depending on the location and options for surgical operations.

Giant inguinal or inguinoscrotal hernias are uncommonly encountered in modern surgical practice but they are a challenging surgical subject. There is an absence of comparative studies due to relatively low number of cases. Usually it is difficult to choose the best procedure and decision must be made intraoperatively in most cases.

Giant inguinoscrotal hernias present formidable surgical problems and the morbidity and mortality associated with their repair are high (Gilleallamudi, 2010). Reduction of large hernia can compromise lung function, and patients may have been previously denied surgery because of the risk of respiratory compromise and development of potentilally fatal cardio-respiratory failure. 
Careful preoperative evaluation, preparation and close postoperative monitoring are essential for successful repair. Before the operation the patient has to have internal, pneumological, cardiological, urological and anesthesiological examination. Other special examinations depend on the patient's co-morbidities (for example after a stroke, patients require neurological examination, etc.). Before the surgery, the patient should visit a plastic surgeon and urologist participating in the operation.

Before the operation it is suitable to perform ultrasonography, CT or MRI, if it is indicated to evaluate the content of the hernial sac. Preoperative colonic evaluation is important because statistics indicates that colon cancer is detected by preoperative barium enema in $1.8-2.5 \%$ of patients who are older than 40 years and have undergone inguinal hernia repair (Terezis et al, 1963, Maxwell et al, 1965, Day et Ferrara, 1986). Moreover, colonic resection may be required as a part of treatment. Barium enema is a preferred method overcolonoscopy for the reason that colonoscopy in the colon within hernial sac, is associated with high risk of colonic perforation (Leisser et al, 1990). Bowel preparation because of a potential bowel resection as a part of the treatment should be considered in all cases.

Hernial sac may contain small and large bowel loops, greater omentum, but also urinary bladder (Ek et al, 2006, Gilleallamudi, 2010, Tahir et al, 2008, Tarchouli et al, 2015, and others). Transverse colon, stomach and kidney along with the ureter are very rarely the content of giant inguinoscrotal hernias (Birnbaum et al, 2011, Udwadia, 1984, Vagholkar et Vagholkar, 2015, Weitzenfeld et al, 1980).

Specific problems associated with the management of giant inguinal hernias are threefold. Firstly, the loss of domain within the abdominal cavity leads to difficulty in reduction of the contents. Diaphragmatic splinting decreases tidal volume and vital capacity and can cause intraabdominal compartment syndrome with respiratory compromise. Postoperative increased abdominal tension heightens the risk of abdominal dehiscence. Secondly, as the hernial defect is large, the risk of recurrence is high. Lastly, the large residual scrotal skin might need excision for cosmetic reasons and scrotal haematoma may be a problem as well (Mohammad et al, 2008).

Intraabdominal hypertension (IAH) can develop because of the disproportion of abdominal domain and the large amount of content in the hernial sac. The high rate mortality is clearly observed following forced reduction of giant inguinal hernia. IAH can immediately develop after reduction of contents or later in the postoperative period due to ileus of the bowel (Trakarnsagna et al, 2014). Excessive increase of intrabdominal pressure generally affects regional blood flow, cardiovascular and respiratory systems. Raised intrathoratic pressure is a result of diaphragm cephalic displacement through increased intraabdominal pressure (Papavramidis et al, 2011). Moreover, the increase of intrathoracic pressure causes an increase of inspiratory rate and mean airway pressure, while tidal volume and pulmonary compliance are reduced. Therefore, vital signs and urine output should be closely monitored. Respiratory support may be needed until ileus starts to resolve. (Mehendale et al, 2000). In the early postoperative period, until patient is not stabilized and eupnoic, it is very important to measure the intraabdominal pressure by a simple intravesicular technique.

There are some additional surgical procedures which can prevent intraabdominal hypertension. In cases that the hernial sac extends below the line between superior borders of patellar bone, ad-

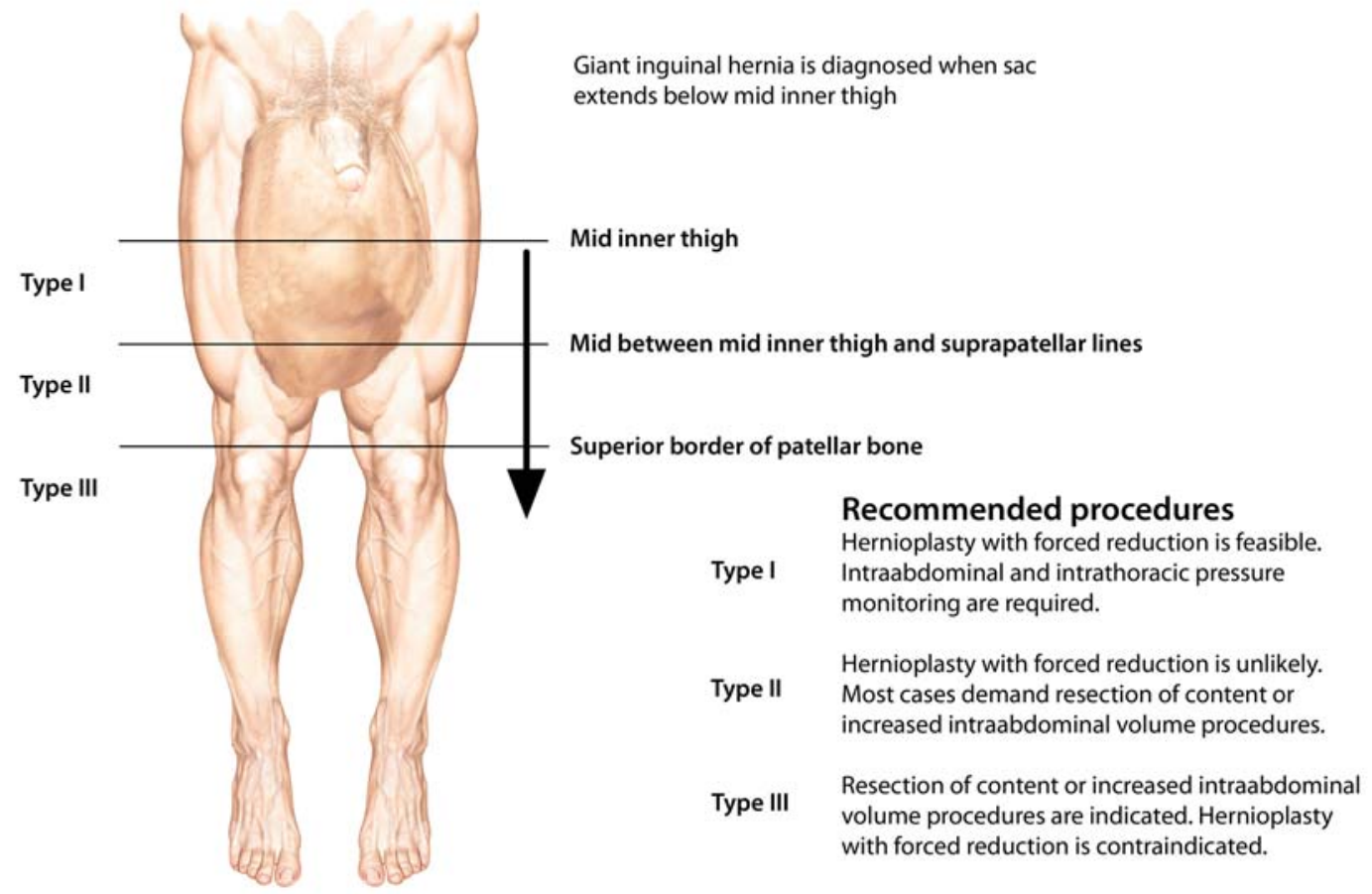

Fig. 9. New classification of giant inguinal hernia and recommended procedure (by Trakarnsagna et al., 2014, modified). 
ditional procedures are almost always needed in addition to forced reduction and simple hernioplasty (Kovachev et al, 2010, Monestiroli et al, 2007, El Saadi et al, 2005, Ek et al, 2006, Imisairi et Hadi, 2011, King et al, 1986, Patsas et al, 2010, Vasilliadis et al, 2010).

The two major techniques required are resection of hernia contents and intraabdominal volume increase procedure. The options include debulking of abdominal contents or enlarging the abdominal cavity. Debulking like extensive bowel resections (total colectomy or hemicolectomy, small bowel resection) and omentectomy were described (Serpell et al, 1988). Disadvantages of this procedures are risk of the failure of anastomosis and infection of prosthesis ussually used for Lichtenstein's tension-free technique.

Progressive arteficially induced pneumoperitoneum has been attempted, but usualy causes enlargement of the hernial sac, rather than the abdominal cavity and is therefore not very effective (Kyle et al, 1990). After all, limitations of this technique are prolonged preoperative hospitalization, spread of air into hernial sac and technical unsuccess. Other possibilities are lengthening of the abdominal wall by mesh or rotation of viable tissue. The advantage of rotation of viable tissue is that it is a single-stage procedure but surgical expretise is required to prevent complications (Valliattu et Kingsnorth, 2008).

In general, giant inguinal or inguinoscrotal hernia is a type of hernia with massive contents inside the hernial sac and limited domain of abdominal cavity. The surgeon's decision regarding the prevention of IAH represents crucial stage of overall management and intraabdominal and intrathoracic pressure must be closely observed after the reduction of any type!

What about orchiectomy? Spermatic cord can be easily stretched as a result of long-standing hernia. In some cases, the spermatic cord is twisted, causing testicular atrophy. Therefore, preoperative testicular examination should be performed in all patients and orchidectomy may be needed to prevent undesirable events (Trakarnsagna et al, 2014).

Recurrence rate of giant scrotal hernias treated by conventional repairs is high. Repair of defects without the use of mesh graft has been described, but most authors in the recent past have preferred the use of mesh (Mohammad et al, 2008).

Large residual scrotal skin might need excision and reconstruction of neoscrotum for cosmetic reasons. However, considerable shrinkage of the scrotal skin occurs because of retraction of the dartos muscle. In addition it may be safer to leave the skin intact as a safety precaution so that if early postoperative severe resipartory compromise occurs the contents can be temporarily shifted back into the scrotum (Mehendale et al, 2000). But for better cosmetic results, a single stage or double staged scrotal reconstruction can be planned (Hodgkinson et McIlrath, 1980).

Scrotal hematoma is often found after the operation and it is usually caused by extensive lysis of dense adhesions. Therefore meticulous hemostasis, firm compression bandage and closed drainage system are important. But even this approach cannot guarantee the prevention of this complication (Mehendale et al, 2000).

Before the operation an informed consent which covers all possible operative techniques and procedures is needed because final decisions is usually made intraoperatively.

\section{Conclusion}

Giant inguinal or inguinoscrotal hernia is an uncommom surgical entity which is challenging for surgeon and specialists involved in the treatment. Surgery is associated with significant morbidity and mortality. Formal open approach is the gold standard for this entity. Laparoscopy has no role whatsover in such cases.

The main problem is the risk of high intra-abdominal pressure after repositioning the hernial sac contents into the abdominal cavity with its known serious consequences to death. Other problems include high risk of recurrence, abundant scrotal skin and scrotal hematoma which is commonly found after the operation. There are several techniques for repair of giant scrotal hernia but most authors in the present have preferred Lichtenstein's tension free technique with mesh. Usually it is difficult to choose the best procedure and decision must be made intraoperatively in most cases. But it is suitable to use individual case by case approach which is more important than strict adherence to any particular technique. Careful preoperative evaluation and preparation of a patient together with intesive intraoperative and postoperative monitoring is the key to achieving good treatment results.

\section{References}

1. Birnbaum DJ, Gregoire E, Campan P, Hardwigsen J, Le Treut YP. A large inguinoscrotal hernia with stomach content. ANZ J Surg 2011; 81 (1-2): 86-87.

2. Brondfiled S, Dhaliwal, G. Giant inguinoscrotal hernia. J Gen Intern Med (Clinical Images) 2016; 31 (12): 1537-1537.

3. Davey WW. Giant inguinal hernia. In: Adeloye A(Ed). Davey's companion to surgery in Africa. Edinburgh: Churchill Livingstone, 1987, 391-393.

4. Day T, Ferrara JJ. Preoperative barium contrast enema in patients with inguinal hernia. South Med J 1986; 79 (11): 1339-1341.

5. Ek EW, Ek ET, Bingham R, Wilson J, Mooney B, Banting SW. Component separation in the repair of a giant inguinoscrotal hernia. ANZ J Surg. 2006, 76: 950-952.

6. El Saadi AS, Al Waden AH, Hamerna S. Approach to a giant inguinoscrotal hernia. Hernia 2005; 9 (3): 277-279.

7. Gilleallamudi SB. Hanging Giant Inguinal Hernia. NJIRM 2010; 1 (4): 47-49.

8. Hodgkinson DJ, Mcllrath DC. Scrotal reconstruction for giant inguinal hernias. Surg Clin North Am 1980; 64: 307-313.

9. Imisairi AH, Hadi SM. Giant inguinal hernia. ANZ J Surg 2011; 81 (6): 488-501.

10. Karthikeyan VS, Sistla SC, Ram D, Ali SM, Rajkumar N. Giant inguinoscrotal hernia - Report of a rare case with literature review. Int Surg 2014; 99: 560-564.

11. King JN, Didlake RH, Gray RE. Giant inguinal hernia. South Med J 1986; 79 (2): 252-253.

12. Kovachev LS, Paul AP, Chowdhary P, Choudhary P, Filipov T. Regarding extremely large inguinal hernias with a contribution of two cases. Hernia 2010; 14: 193-197.

13. Kyle SM, Lovie MJ, Dowle CS. Massive inguinal hernia. Br J Hosp Med 1990; 43: 383-384. 
472-478

14. Lau W.Y. History of treatment of groin hernia. World J Surg 2002; 26 (6): 748-759.

15. Leisser A, Delpre G, Kadish U. Colonoscope incarceration: an avoidable event. Gastrointest Endosc 1990; 36 (6): 637-638.

16. Maxwell JW, Davis WC, Jackson FC. Colon carcinoma and inguinal hernia. Surg Clin North Am 1965; 45 (5): 1165-1171.

17. Mehendale FV, Taams KO, Kingsnorth AN. Repair of a giant inguinoscrotal hernia. Br J Plast Surg 2000; 53: 525-529.

18. Mohammad T, Ahmed FU, Seenu V. Giant inguinoscrotal hernia: Case report and management principles. Int J Surg 2008; 6: 495-497.

19. Monestiroli M, Bondurri A, Gandini F, Lenna G, Vellini S, Danelli P. Giant inguinoscrotal hernia. Tech Coloproctol 2007; 11 (3): 283-285.

20. Papavramidis TS, Marinis AD, Pliakos I, Kesisoglou I, Papavramidou N. Abdominal compartment syndrome-intraabdominal hypertension: defining, diagnosing and managing. J Emerg Trauma Shock 2011; 4 (2): 279-291.

21. Patsas A, Tsiaousis P, Papaziogas B, Koutelidakis I, Goula C, Atmatzidis K. Repair of a giant inguinoscrotal hernia. Hernia 2010; 14 (3): 305-307.

22. Serpell JW, Polgase AL, Anstee EJ. Giant inguinal hernia. ANZ J. Surg, 1988, 58: 831-834.

23. Tahir M, Ahmed FU, Seenu V. Giant inguinoscrotal hernia: case report and management principles. Int J Surg 2008; 6: 495-497.
24. Tarchouli M, Ratbi MB, Bouztroud M, Aitidir B, Ali AA, Bounaim A, Sair K. Giant inguinoscrotal hernia containing intestinal segments and urinary bladder successfully repaired by simple hernioplasty technique: a case report. J Med Case Rep 2015; 9: 276-282.

25. Terezis NL, Davis WC, Jackson FC. Carcinoma of the colon associated with inguinal hernia. N Engl J Med 1963; 268: 774-776.

26. Trakarnsagna A, Chinswangwatanuka V, Methasate A, Swansgr J, Phalanusitthepha CH, Parakonthun T, Taweerutchana V, Akaraviputh T. Giant inguinal hernia: Report of a case and reviews of surgical techniques. Int J Surg Case Rep 2014; 5 (11): 868-872.

27. Udwadia TE. Stomach strangulated in inguinal hernia presenting with hematemesis. Int Surg 1984; 69 (2): 177-179.

28. Vagholkar K, Vagholka, S. Surgical management of giant inguinoscrotal hernias. Int J Surg J 2015; 2 (4): 693-695.

29. Valliattu AJ, Kingsnorth AN. Single-stage repair of giant inguinoscrotal hernias using the abdominal wall component separation technique. Hernia 2008; 12 (3): 329-330.

30. Vasilliadis K, Knaebel HP, Djakovic N, Nyarangi-Dix J, Scahmidt J, Bucher M. Challenging surgical management of a giant inguinoscrotal hernia: report of a case. Surg Today 2010; 40 (7): 684-687.

31. Weitzenfeld MB, Brown BT, Morillo G, Bloc NL. Scrotal kidney and ureter: an unusual hernia. J Urol 1980; 123 (3): 437-438.

Received March 13, 2017. Accepted April 14, 2017. 